\title{
Performance Tradeoffs in the Design of Photoacid Generators for ArF Lithography
}

\author{
James F. Cameron, Nicholas Chan, Kathryn Moore and Gerd Pohlers \\ Shipley Company, Microelectronic Materials Research and Development \\ Laboratories,
}

455 Forest Street, Marlborough MA 01752

\begin{abstract}
Photoacid generation is a critical step in the application of chemically amplified (CA) resist technology. During the key exposure step, a catalytic amount of a strong Brpnsted acid is released within these resists. The photoacid is subsequently used in a post-exposure bake step to catalytically react with the resist polymer. In the case of a positive tone resist, an acid sensitive polymer is deprotected to render the exposed areas soluble in dilute aqueous base thereby allowing for pattern development. As the semiconductor industry begins to focus on developing $193 \mathrm{~nm}$ photoresists for production, it is important to identify and understand differences between prototype $193 \mathrm{~nm}$ CA resists and current state of the art $248 \mathrm{~nm}$ production worthy photoresists. The major difference between 193 and $248 \mathrm{~nm}$ photoresists is the exposure wavelength, which is reduced to achieve higher resolution based on the Rayleigh equation. However, this change in wavelength has several ramifications: Firstly, the tried, tested and true phenolic polymers used in DUV resists are too absorbent to be used for 193 $\mathrm{nm}$ application and had to be replaced by low absorbing, non-aromatic systems. Second, since even these new platforms are still more absorbing at $193 \mathrm{~nm}$ than the phenolic matrices are at $248 \mathrm{~nm}$, the PAG loading had to be lowered significantly in order to keep the overall absorbance of the resist down.

This paper describes the results of our systematic studies on understanding the reasons for observed differences in photoacid generating efficiency between 193 and $248 \mathrm{~nm}$ chemically amplified resist systems. First, the wavelength effect is studied by comparing the relative acid generating efficiency of onium type PAGs in a prototype $193 \mathrm{~nm}$ and a DUV photoresist at both $193 \mathrm{~nm}$ and 248 $\mathrm{nm}$ exposure. Second, the photoacid generating efficiency for these PAGs at $248 \mathrm{~nm}$ is compared in both phenolic and non-phenolic based photoresists to probe resist polymer matrix effects. Third, these experiments were repeated while varying the PAG loading in order to probe whether there is an effect of PAG loading on acid generation efficiency. Lastly, by performing all of these studies on two different onium PAG classes (iodonium and sulfonium salts), the impact of the PAG chromophore on acid generation efficiency in both sensitized and unsensitized environments was probed. In all these studies, the C-parameter method is used to determine the quantum yield of photoacid generation.

First, the exposure wavelength was found to play a significant role in determining the acid generation efficiency of both PAGs, namely efficiency significantly decreases when switching exposure wavelength from 248 to $193 \mathrm{~nm}$. Second, it was also found that the change in the resist matrix polymer has a profound impact on the manner in which acid is generated: The phenolic matrix enables sensitized acid generation via electron transfer from the matrix to the PAG, whereas in the acrylate polymer only direct acid generation is observed. Due to the different oxidation potential of iodonium and sulfonium PAGs, the matrix effect impacts the photoacid generation efficiency of the two PAGs very differently. This is apparent in the observed change when going from the phenolic to the methacrylate matrix. Lastly, the presence of the sensitized channel is also responsible for the observed impact of PAG loading in the phenolic polymer, which is largely absent in the acrylate matrix.
\end{abstract}

Keywords: acid quantification, acid generating efficiency, sensitization, quantum yield, Cparameter, photoacid generator, deep UV and $193 \mathrm{~nm}$ chemically amplified resists. 


\section{Introduction}

With commercialization of $193 \mathrm{~nm}$ resists well underway, it is clear that ArF lithography will be the technology to replace DUV photoresists for the production of the next generations of integrated circuits. Significant obstacles had to be overcome in the development of production worthy $193 \mathrm{~nm}$ platforms, mainly in the polymer area. This is due to the fact that the traditional phenolic polymers employed in DUV resists are too absorbing at 193 $\mathrm{nm}$ because of the high intensity absorption band the substituted phenyl chromophore exhibits right around that wavelength. Thus, over the years many $193 \mathrm{~nm}$ resist polymer platforms have been developed [1] which are characterized by the absence of any aromatic groups, thereby reducing the absorbance of the polymer to a level reasonably close to that found for phenolic polymers at $248 \mathrm{~nm}$. On the other hand, much less attention has been devoted to developing specific $193 \mathrm{~nm}$ PAGs [2], partially because a radical departure from the existing DUV PAG technology was not deemed necessary. Nevertheless, there are still important criteria to be considered for the successful development of new, specific $193 \mathrm{~nm}$ PAGs. Many of the design criteria for successful $193 \mathrm{~nm}$ PAGs largely stem from an appreciation of the differences in the roles of the new $193 \mathrm{~nm}$ aliphatic polymer platforms and traditional $248 \mathrm{~nm}$ phenolic materials with regard to acid generation.

Given the importance of acid catalyzed chemistry in today's state of the art DUV photoresists, as well as future lithographic technologies, it is critical to develop a deep understanding of the role of photoacid generation in the lithographic process. Over the last few years, we have focused on the impact of photoacid generators on DUV resist performance $[3,4]$. We have emphasized the importance of the structure of the photoacid generator in terms of both PAG chromophore and photoacid structure $[3,4]$.

In this paper, we continue in this vein with emphasis on the photoacid generation step of the lithographic imaging process, now focussing on the differences in acid generation efficiency observed for the two wavelengths. This is done by quantifying the amount of acid that is photogenerated in real resist systems at key exposure doses. Several successful methods for the direct measurement of photogenerated acid have been devised. These include spectrophotometric methods [5-9], an ion conductivity method [10] and a novel acid-base type titration method [11].

By far the most common method for acid quantification is the spectrophotometric detection of photogenerated acid using an acid sensitive dye. In such spectrophotometric methods, the change in absorbance or fluorescence of a dye upon protonation is used to quantify the amount of photogenerated acid in exposed resist wafers. Typically, the acid is detected upon extraction of the exposed resist. The labor intensive nature of the resist wafer extraction prompted Szmanda et. al. [11] to develop an alternative method for acid quantification. This method, known as the Dill Cparameter method, relies on the titration of the photogenerated acid against increasing amounts of added base. Since the dose to clear (Eo) decreases linearly with the concentration of added base, it is possible to infer the amount of acid generated by each exposure dose and thus ascertain the Dill $\mathrm{C}$ parameter. We recently validated the C-parameter method by comparison with standard spectrophotometric methods [12] and in a separate study, we reported some key limitations of the Cparameter method [13]. Armed with an accurate value for the C-parameter, the quantum yield of acid generation can be readily calculated assuming the resist absorbance and formulation make-up are known.

In this paper, we focus on elucidating the dependence of the acid generating efficiencies of triphenylsulfonium triflate and di-(4-tertbutylphenyl)iodonium triflate, two widely used PAGs, on the three key parameters that change when going from DUV to $193 \mathrm{~nm}$ resists, namely the matrix, exposure wavelength and loading. Therefore, we study the photoacid efficiency in a DUV phenolic and a $193 \mathrm{~nm}$ acrylate polymer system upon $248 \mathrm{~nm}$ exposure using an equimolar loading for both PAGs. This comparison isolates the effect of the matrix on the PAG efficiency while keeping all the other parameters constant. These values are then compared with efficiencies obtained at $193 \mathrm{~nm}$ irradiation in the acrylic matrix to study the effect of the wavelength. The loadings used in these experiments were a standard $248 \mathrm{~nm}$ resist PAG loading for the experiments in the phenolic matrix ("high" loading) and a standard $193 \mathrm{~nm}$ resist loading for the experiments in the acrylate resist 
("low" loading). Finally, both resists were run at the two different loading levels (high and low loading) to find out if and how PAG concentration influences the photoacid generation quantum yield.

\section{Experimental}

\subsection{Formulation}

The $248 \mathrm{~nm}$ resist formulations were based on the ESCAP resist technology using a partially blocked terpolymer of 4-hydroxystyrene, styrene and t-butyl acrylate (1) [14]. The $193 \mathrm{~nm}$ resist formulations were based on a Fujitsu-like [15] resist containing a copolymer of a lactone methacrylate and methyl-2-adamantyl methacrylate (2):<smiles>CC(C)(C)CC(CC(C)(C)C)C(C(=O)OC(C)(C)C)c1ccccc1</smiles>

1<smiles>CC(C)(C)CC(C)(C)C(=O)OC1(C)C2CC3CC(C3)C2C1(C)CC(C)(C)C</smiles>

2

For each set of experiments the two PAGs were formulated on an equimolar basis. The PAGs used in this study were di-(4-tert-butylphenyl)iodonium triflate (DTBPIOTf) and triphenylsulfonium triflate (TPSOTf). The loadings used were a standard 248 $\mathrm{nm}$ resist PAG loading for the experiments in the phenolic matrix, hereafter referred to as "high" loading and a standard $193 \mathrm{~nm}$ resist loading for the experiments in the acrylate resist, hereafter referred to as "low" loading.

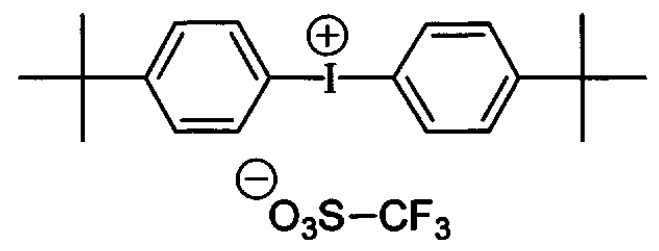

DTBPIOTf<smiles>O=[S-](c1ccccc1)c1ccccc1</smiles>

TPSOTf

\subsection{Absorbance Data}

Resist film absorption spectra were recorded on resist coated quartz wafers using a Varian CARY 13 spectrophotometer. For the phenolic system, resist films were coated on quartz wafers and baked at $130^{\circ} \mathrm{C}$ for 60 seconds to give a thickness of approximately one micron. For the acrylate system, resist films were coated on quartz wafers and baked at $120^{\circ} \mathrm{C}$ for 60 seconds to give a film thickness of the order 0.6-0.7 micron. In each case, the absorbance was averaged over four measurements per wafer and then normalized to one micron thickness. Solution absorption spectra were run in acetonitrile using $1 \mathrm{~cm} \times 1 \mathrm{~cm}$ Suprasil quartz cells.

\subsection{Film Densities}

The densities of the coated resist films were determined by coating 6" silicon wafers with the respective formulation to a thickness close to that used for the actual efficiency experiments, weighing the wafers, dissolving the resist film in THF, drying and weighing the clean wafer again. The difference in mass is the weight of the resist film; which together with its volume (from the thickness and coated area) allows for the calculation of the normalized density. The values obtained in this way are $1.15 \mathrm{~g} \mathrm{~cm}^{-3}$ (phenolic matrix) and $1.39 \mathrm{~g} \mathrm{~cm}^{-3}$ (acrylate matrix). For comparison, the literature values found for poly(hydroxystyrene) and 
poly(methylmethacrylate) are 1.06 and $1.19 \mathrm{~g} \mathrm{~cm}^{-3}$, respectively [16]. The reason for the somewhat higher values determined by us is most likely due to the presence of the small molecules in the resist formulation (residual solvent, PAG, surfactant, base additive) which increase the density relative to the pure polymer.

\subsection{C-Parameter / Quantum Yield Calculations}

In order to calculate the quantum yields of acid generation, the first order rate constant for photoacid generation (or C-parameter) had to be determined (equation 3). A convenient method employing the dose to clear to calculate the C-parameter has recently been developed and was our method of choice. The experimental procedure for determining C-parameters is as follows:

For each PAG to be studied, five samples of prototype chemically amplified resist were prepared as described above. The resists were identical except for the amount of base quencher, which was varied from $0,2.5,5.0,7.5$ and $10 \mathrm{~mol} \%$ relative to PAG. The resist formulations were filtered through a $0.20 \mu \mathrm{m}$ Teflon filter and spin coated onto $600 \AA$ thick AR3 for the $248 \mathrm{~nm}$ (phenolic) resist formulation or $820 \AA$ thick AR19 for the $193 \mathrm{~nm}$ (acrylate) resist formulation. Formulations were coated to a thickness of $7000 \pm 25 \AA(248 \mathrm{~nm}$ exposures) or $3900 \pm 25 \AA$ (193 $\mathrm{nm}$ exposures). The resists were coated, baked and developed on a TEL Track MARK 8 system (248 $\mathrm{nm}$ exposures) or an LFI Polaris track (193 nm exposures). The phenolic resist coated wafers were soft baked at $130^{\circ} \mathrm{C}$ for 60 seconds, post exposure baked at $130^{\circ} \mathrm{C}$ for 90 seconds and developed in LDD-26W using a 45 second single puddle process. The process conditions for the acrylate resist system were a softbake at $120^{\circ} \mathrm{C}$ for 60 seconds and a postexposure bake at $120^{\circ} \mathrm{C}$ for 60 seconds followed by development in CD-26W using a 45 second single puddle process. Exposures were performed in an open frame mode on a GCA XLS 7800 Stepper $(0.53 \mathrm{NA}, 0.74 \sigma)$ and ISI Microstepper (0.60NA, $0.70 \sigma$ ) for 248 and $193 \mathrm{~nm}$ exposures, respectively. The photospeed or energy to clear (Eo) was defined as the exposure dose necessary to remove the resist film upon development. The photospeed was determined for each resist formulation. The slope of the line of the base / PAG mole ratio plotted against photospeed is the uncorrected C-parameter. The corrected C-parameter is obtained by multiplying the uncorrected C-parameter by the factor A / $\left(1-\mathrm{e}^{-\mathrm{A}}\right)$, where $A$ equals the total absorbance of the film at the exposure wavelength [11].

Besides the photolysis rate constant, information on the resist absorbance and formulation make-up are also required to calculate the quantum yield for photoacid generation. The requisite experimental details necessary to determine key parameters for quantum yield calculation are described in the previous experimental sections. The specific details on the quantum yield calculations are described in the following section:

$$
\begin{gathered}
\Phi=\frac{\text { Number of Photochemical Events }}{\text { Number of Photons Absorbed }} \\
\text { Equation } 1
\end{gathered}
$$

In the case of the photoacid generation process, the quantum yield can be explicitly defined by Equation 2.

$$
\Phi=\frac{\text { Number of Photoacid Molecules Generated }}{\text { Number of Photons Absorbed }}
$$

Equation 2

The numerator and denominator of Equation 2, can be further expanded as shown in Equations 3 and 4 respectively.

No of Photoacid Molecules $\left(\mathrm{H}^{+}\right)$Generated $=$
$\%$ PAG(solids) $\times \frac{\text { FT } \times \text { Exp Area } \times \rho}{\text { PAG MW }} \times \mathrm{C} \times$ NA

\section{Equation 3}

Where, $\%$ PAG $=\%$ PAG loading relative to solids PAG MW = Molecular weight of PAG $\left(\mathrm{g} \mathrm{mol}^{-1}\right)$

FT $=$ Film thickness $(\mathrm{cm})$

$\mathrm{C}=$ First order photolysis rate constant $\left(\mathrm{cm}^{2} \mathrm{~mJ}^{-1}\right)$

Exp. Area $=$ Exposure area $\left(\mathrm{cm}^{2}\right)$

$\mathrm{N}_{\mathrm{A}}=$ Avogadro's number $\left(\mathrm{mol}^{-1}\right)$

$\rho=$ Density of film $\left(\mathrm{g} \mathrm{cm}^{-3}\right)$

No. of Photons Absorbed =

Fraction of Light Absorbed $x \frac{\text { No of Photons in } 1 \mathrm{mJcm}^{-2}}{\text { Energy of one Photon }}$

Equation 4 
Further expansion of Equation 4 is needed to give a working equation, Equation 5, to determine the number of photons absorbed (denominator in Equation 2).

$$
\begin{gathered}
\text { No of Photons Absorbed }= \\
1-10-\left(a b c^{\prime}+\text { Aother }\right) \times \frac{0.0001 \times \lambda}{\text { hc }}
\end{gathered}
$$

Equation 5

Where, $a=$ PAG absorption $\left(\mu \mathrm{m}^{-1} \mathrm{wt}^{-1} \mathrm{H}^{-1}\right)$

b $=$ Film thickness $(\mu \mathrm{m})$

$c^{\prime}=$ PAG concentration (wt $\left.\%\right)$

$\mathrm{A}_{\text {other }}=$ Combined absorption from all resist components except the PAG $\left(\mu \mathrm{m}^{-1}\right)$

$\mathrm{h}=$ Planck's constant $(\mathrm{J} \mathrm{s})$

$\mathrm{c}=$ Speed of light $\left(\mathrm{cm} \mathrm{s}^{-1}\right)$

$\lambda=$ Exposure wavelength $(\mathrm{cm})$

\section{Results and Discussion}

\subsection{Phenolic versus methacrylate polymer - the} matrix effect

The corrected C-parameters, quantum yields of acid generation $\left(\Phi_{\text {acid }}\right)$, normalized film absorbencies and doses to clear (Eo) are shown in Table 1: First, it seems worthwhile to again define the term efficiency as we use it throughout this paper. Our definition of PAG efficiency is the ratio of the amount of acid photogenerated acid to light absorbed by the PAG, i.e., this ratio describes how efficiently a PAG can "make use" of the light it has absorbed. This is essentially the definition of the quantum yield of photoacid generation as given in the experimental section above. It should be noted that this definition focuses on the actual amount of light absorbed, rather than the incident light. While the incident dose may be an important parameter, at least from the lithographic point of view, it is meaningless for the purpose of describing how efficient a PAG converts energy into acid, since it does not contain any information on how much of the light is actually absorbed by the PAG. For example, two PAGs with very different efficiencies can still yield the same amount of photogenerated acid with the same amount of incident light if they absorb different amounts of that incident light. In other words, relating the amount of generated acid to the incident light and absorbed light only yields the same result if the samples are equiabsorbent.

Taking that into account, it is apparent that the corrected C-parameter is not a measure of the efficiency of a PAG, but merely the first order rate constant for the generation of photoacid. While this statement may seem contradictory at first, one has to consider that the $\mathrm{C}$-parameter is related to the incident dose, not the light actually absorbed by the PAG. Thus, the $\mathrm{C}$ values obtained for different PAGs can serve as a measure for efficiency only if

\begin{tabular}{|c|c|c|c|c|c|c|c|}
\hline PAG & Matrix & $\begin{array}{c}\text { PAG } \\
\text { loading }\end{array}$ & $\begin{array}{c}\text { Exposure } \\
\text { wavelength }\end{array}$ & $\begin{array}{c}\text { Film abs. } \\
\mu \mathbf{m}^{-1}\end{array}$ & $\begin{array}{c}\text { Corrected C } \\
\mathrm{cm}^{2} \mathbf{~ m J}^{1} \\
\end{array}$ & $\begin{array}{l}\Phi_{\text {acid }} \\
\text { total }\end{array}$ & $\begin{array}{c}\text { Eo } \\
\mathrm{mJ} \mathrm{cm} \mathbf{c m}^{-2}\end{array}$ \\
\hline TPS & \multirow[t]{2}{*}{ phenolic } & \multirow[t]{2}{*}{ low } & 248 & 0.241 & 0.055 & 0.27 & 8.7 \\
\hline DTBPI & & & & 0.250 & 0.057 & 0.28 & 8.1 \\
\hline TPS & \multirow[t]{2}{*}{ acrylate } & \multirow[t]{2}{*}{ low } & 248 & 0.100 & 0.047 & 0.63 & 4.8 \\
\hline DTBPI & & & & 0.111 & 0.018 & 0.22 & 12.2 \\
\hline TPS & \multirow[t]{2}{*}{ acrylate } & \multirow[t]{2}{*}{ low } & 193 & 0.538 & 0.029 & 0.11 & 7.2 \\
\hline DTBPI & & & & 0.496 & 0.012 & 0.05 & 20.1 \\
\hline TPS & \multirow[t]{2}{*}{ acrylate } & \multirow[t]{2}{*}{ high } & 193 & 0.885 & 0.026 & 0.13 & $7.3^{*}$ \\
\hline DTBPI & & & & 0.829 & 0.008 & 0.04 & $23.2^{*}$ \\
\hline TPS & \multirow[t]{2}{*}{ phenolic } & \multirow[t]{2}{*}{ high } & 248 & 0.299 & 0.042 & 0.33 & $5.2^{*}$ \\
\hline DTBPI & & & & 0.320 & 0.051 & 0.39 & $4.8^{*}$ \\
\hline
\end{tabular}
the samples were equiabsorbent.

TABLE 1: Corrected C-parameters, quantum yields of acid generation, normalized film absorbencies and doses to clear for both PAGs under different conditions.

(*Note: These values cannot be compared to one another due to slight variations in the PAG to base ratio for these samples). 
If this is not the case, as in our experiments, only the quantum yield is a true gauge for PAG efficiency. The finding that the C-parameters nevertheless do correlate with the quantum yields within all of the five TPS/DTBPI pairs in Table 1 is due to the fact that the samples were close to equiabsorbent (Table 1). This stems from the fact that each TPS/DTBPI sample pair was loaded at an equimolar PAG loading and the PAGs have relatively similar extinction coefficients at the two wavelengths under investigation. For the same reason the Eo values track the quantum yields and $\mathrm{C}$ parameters for a given PAG pair in Table 1, whereas there is no correlation between the iodonium/sulfonium PAG pairs, because the absorbencies were very different, ranging from 0.1 to almost 0.9 (Table 1).

As can be seen from Table 1, the $248 \mathrm{~nm}$ quantum yields of the two PAGs in the phenolic matrix are essentially equal, whereas there is a pronounced difference in the acrylate system. The value for DTBPI decreases by $21 \%$, whereas the TPS efficiency increases by $133 \%$ on going from the phenolic to the acrylate matrix at $248 \mathrm{~nm}$. This result can be explained if one considers the different acid generating mechanisms in the two polymers. It has been known for some time that in a phenolic matrix a dual mechanism is operative for photoacid generation by onium salts [17] (Scheme 1). One is the direct photochemical pathway which follows the initial absorption of a photon by the PAG, the other involves indirect excitation via a sensitized pathway. In this latter mechanism, initial absorption of a photon by the polymer is followed by electron transfer from the phenol or, less likely, benzene chromophore of the polymer (donor) to the PAG (acceptor) ultimately liberating a proton, which together with the onium counterion constitutes the photogenerated acid.

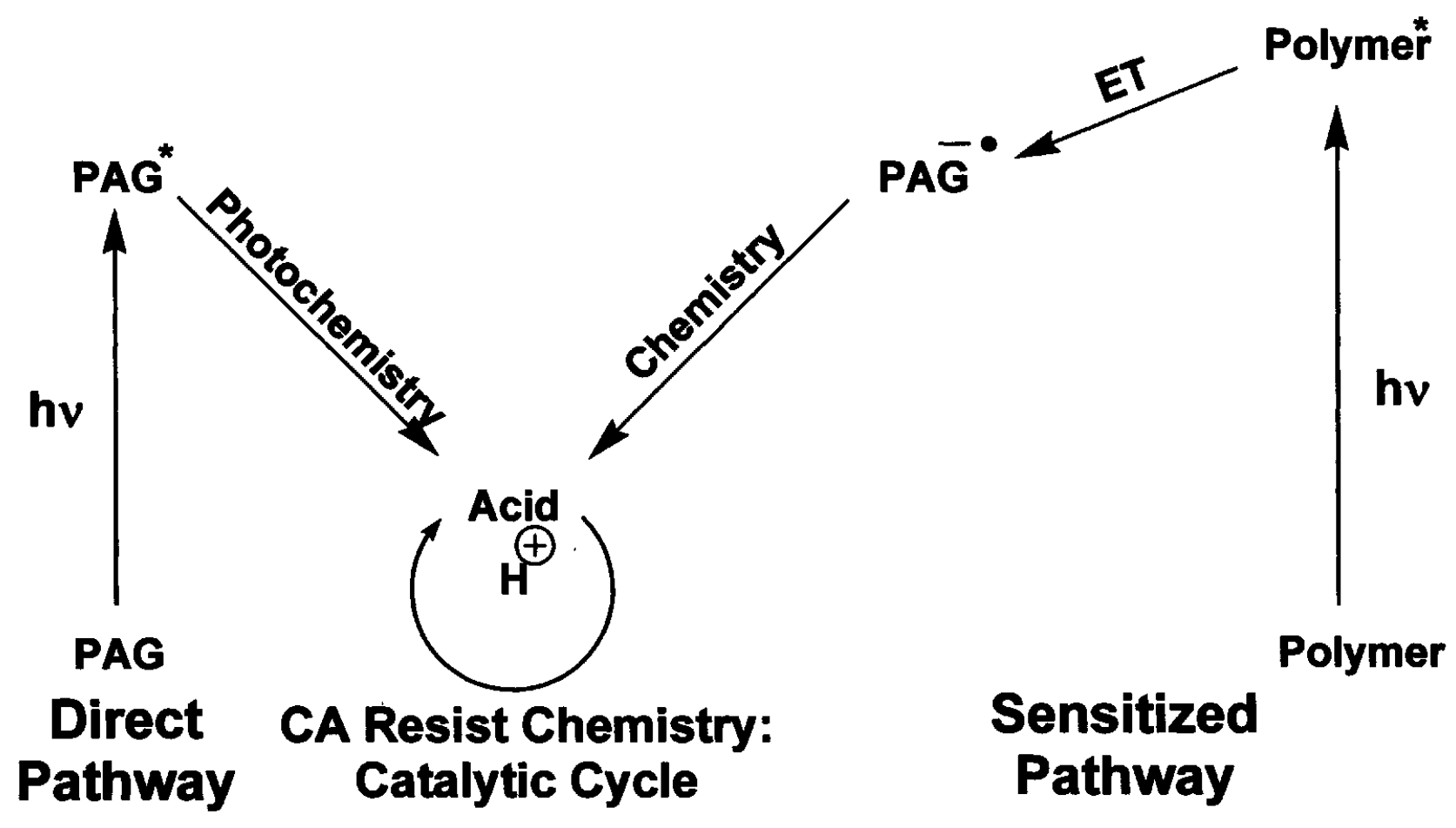

SCHEME 1 
The switch from the phenolic to an acrylate polymer effectively shuts down the sensitization channel due to the poor electron donor capabilities of the latter. This decreased capability to serve as electron donor should manifest itself in the oxidation potentials for the two polymers. Since electrochemical data on the polymers were not available, we had to resort to model compounds instead. Benzene and phenol were chosen as models for the phenolic polymer. For the acrylate system, an ester such as ethyl acetate would have been a reasonable model, but we were unable to find any data reflecting the ease of oxidation ( $\left.E_{o x}, I P\right)$ for aliphatic esters. We believe this is indicative of the fact that such aliphatic esters are very reluctant to oxidation. But even though we cannot quantify our statement, it can be taken as a fact that phenol or even benzene is much more easily oxidized than ethyl acetate.

Having established the absence of the sensitized pathway in the acrylate polymer, the observed difference between the two quantum yields in this platform must simply be due to the difference in acid generation efficiency between the iodonium and sulfonium PAG in the absence of sensitization. A more detailed discussion of this effect is given below (see section 3.3 Sulfonium vs iodonium - the chromophore effect). However, the presence of the sensitized channel alone cannot explain the very different relative efficiencies in the two matrices. For that, sensitization has to affect both PAGs differently. This difference can easily be rationalized if one considers the difference in the reduction potential of the two PAGs and the model sensitizers together with their excited state energies (Table 2).

The data in Table 2 allows the calculation of the change in free energy for electron transfer (Table 3) from the model compound to the onium salts using the Rehm-Weller equation (Equation 6) [21]:

$$
\Delta G_{E T}=E_{o x}(D)-E_{r e d}(A)-E_{S_{1}}\left(D^{*}\right)+C
$$

Equation 6

\begin{tabular}{|c|c|c|c|}
\hline & $\begin{array}{c}\text { Redox } \\
\text { potential } \\
/ \mathbf{V}\end{array}$ & $\begin{array}{c}\mathbf{E}_{\mathbf{S}} / \mathbf{e V} \\
(\mathbf{k J} / \mathbf{m o l})\end{array}$ & $\begin{array}{c}\mathbf{E}_{\mathrm{T}} / \mathbf{e V} \\
(\mathbf{k J} / \mathbf{m o l})\end{array}$ \\
\hline TPS & -1.2 & 4.12 & 3.21 \\
& & $(399)$ & $(311)$ \\
\hline DTBPI & -0.7 & - & 2.78 \\
& & - & $(269)$ \\
\hline Phenol & 1.04 & $\begin{array}{c}4.47 \\
(433)\end{array}$ & $\begin{array}{c}3.54 \\
(343)\end{array}$ \\
\hline Benzene & 2.30 & 4.77 & 3.64 \\
& & $(462)$ & $(352)$ \\
\hline
\end{tabular}

TABLE 2: Redox parameters and singlet and triplet excited state energies for the two PAGs and the model compounds. Data for the sensitizers taken from ref. 18, for TPS from ref. 17 and 19, and for DTBPI from ref. 20.

Here, $E_{S 1}(D)$ and $E_{o x}(D)$ are the excited state energy and halfwave oxidation potential of the donor, and $E_{\text {red }}$ (A) refers to the halfwave reduction potential of the acceptor, $\mathrm{C}$ represents the Coulomb term and is neglected for our calculation. The idea behind this calculation is that $\Delta \mathrm{G}$ correlates, via the classical transition state theory, with the rate constant for the electron transfer. That rate constant, in turn, can be expected to correlate with the quantum yield of acid generation. As can be seen from Table 3, the iodonium salt shows a more negative free energy for electron transfer and can be expected to be more readily sensitized. This translates into a higher quantum yield for the sensitized pathway for the iodonium PAG, compared to the sulfonium compound (Table 1). The second factor that works in favor of the iodonium compound when changing polymers is that in the phenolic matrix, a significant portion of the light is now absorbed by the polymer, whereas in the acrylate matrix virtually all photons absorbed by the resist are absorbed by the PAG. This competition for the incident light adversely affects the TPS PAG more because it is the far more efficient PAG upon direct excitation and "sharing" the available photons with the less efficient sensitized pathway has a more negative impact on its quantum yield. These two effects combined are the reason that the iodonium efficiency stays about constant, while the TPS efficiency increases sharply when changing from the phenolic to the acrylate polymer upon $248 \mathrm{~nm}$ exposure. 


\begin{tabular}{|c|c|c|c|c|}
\hline & \multicolumn{2}{|c|}{ TPS } & \multicolumn{2}{c|}{ DTBPI } \\
\hline & $\mathbf{S}_{\mathbf{1}}$ & $\mathbf{T}_{\mathbf{1}}$ & $\mathbf{S}_{\mathbf{1}}$ & $\mathbf{T}_{\mathbf{1}}$ \\
\hline Phenol & -2.23 & -1.30 & -2.73 & -1.8 \\
& $(-216)$ & $(-126)$ & $(-264)$ & $(-174)$ \\
\hline Benzene & -1.27 & -0.14 & -1.77 & -0.64 \\
& $(-123)$ & $(-14)$ & $(-171)$ & $(-62)$ \\
\hline
\end{tabular}

TABLE 3: Calculated change in free energy in $\mathrm{eV} /$ $(\mathrm{kJ} / \mathrm{mol})$ for electron transfer from the model compounds to the PAGs.

Comparing the values in Table 3 reveals that the change of free energy is more negative for the singlet states due to their higher energy. This, however, does not necessarily mean that the partition of the sensitized acid generating pathway is in favor of the singlet state. The contributions of the two states depend not only on the change in free energy, but also on the relative population of the two states. Another factor is the relative lifetimes of both states, since the quenching efficiency for an electronically excited state of a molecule increases with its lifetime. A more detailed assessment of these two factors and how they may influence the relative distribution of singlet to triplet channel is given below:

1. The intersystem crossing quantum yields [18] for phenol and benzene in a non-polar solvent are 0.32 and 0.25 , respectively, i.e., they are of appreciable magnitude and the triplet state can be expected to be populated reasonably efficiently.

2. The lifetimes [18] of the two states is $2.1 \mathrm{~ns}\left(\mathrm{~S}_{1}\right)$ and $3.3 \mu \mathrm{s}\left(\mathrm{T}_{1}\right)$ for phenol. The benzene singlet lifetime in solution is $34 \mathrm{~ns}\left(\mathrm{~S}_{1}\right)$, whereas the triplet state is very short lived due to very fast photochemical processes originating from that state. However, the lifetime of the triplet states in a rigid matrix will be considerably longer than in a low viscosity solution, whereas the lifetime of the singlet state is not significantly affected by the matrix.

Given that the hydroxyphenyl group is more likely to act as donor than the phenyl group (Table 3), the triplet contribution to the overall acid production in the sensitized manifold of the acid generating scheme should be considerable and may in fact be larger than the singlet pathway.

\section{$3.2248 \mathrm{vs} 193 \mathrm{~nm}$ - the wavelength effect}

The comparison of rows three to six in Table 1 shows the wavelength dependence of acid generating efficiency. The values indicate a decrease in efficiency for both PAGs by about $77 \%$ (DTBPI) and $83 \%$ (TPS) when going from 248 to $193 \mathrm{~nm}$ irradiation. This result has to be taken as is, since the quantum yield of acid generation of a PAG in a certain (non-sensitizing) matrix and wavelength is an inherent property of the PAG. The fact that the efficiency actually decreases, even though the energy per photon increases when going from $248(8.02 \mathrm{x}$ $10^{-19} \mathrm{~J} /$ photon $)$ to $193 \mathrm{~nm}\left(1.03 \times 10^{-18} \mathrm{~J} /\right.$ photon $)$, may seem counterintuitive at first. However, one must not forget that the quantum yield for a certain photochemical process from a given excited state depends only on the ratio of the rate constant for that particular process to the sum of all other rate constants which depopulate that same state. That means that the actual energy of the excited state does not influence that quantum yield, given that it is high enough to enable an exergonic reaction. Thus, the observed difference could arise from the fact that the two excited states have different relaxation processes to compete with, resulting in a different population of the acid generating exciting state(s). Comparison of the absorption spectra of the two PAGs in both matrices (Fig. 1) and in acetonitrile (Fig. 2) reveals at least two separate bands, which belong to different electronic transitions. If one assumes that the spectra can be regarded as perturbed benzene spectra, which is a reasonable first order approximation, then the long wavelength band corresponds to the symmetry forbidden ${ }^{1} L_{b}$ band of benzene and the short wavelength band to the ${ }^{1} L_{a}$ and ${ }^{1} B$ band. Therefore, excitation at $193 \mathrm{~nm}$ generates a different excited state than $248 \mathrm{~nm}$ excitation, which, as outlined above, may be responsible for the differences between the two excitation wavelengths. 


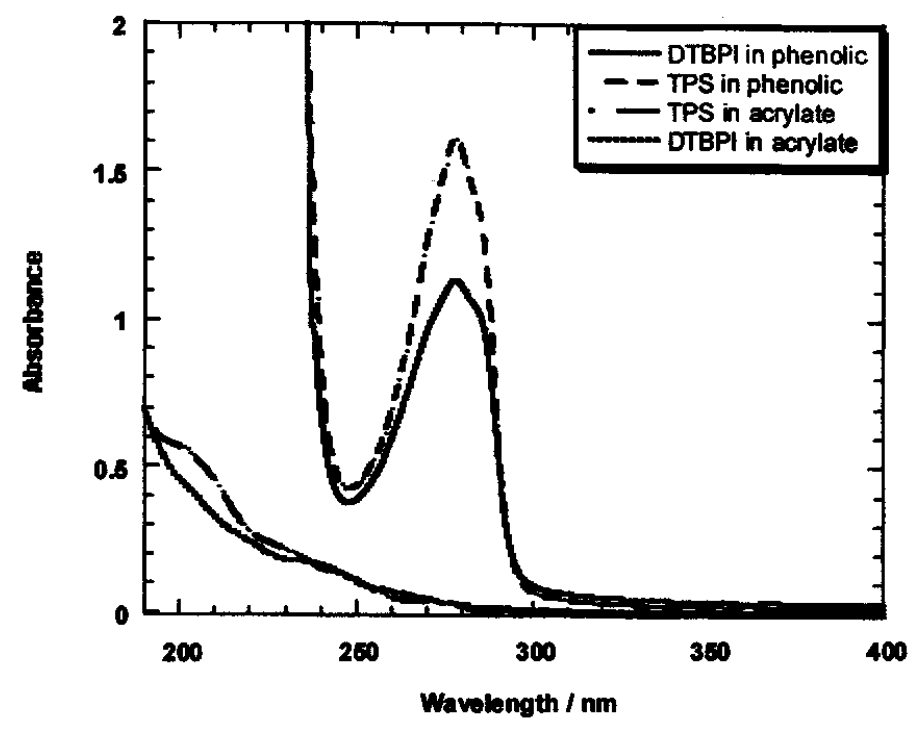

FIGURE 1

Another possible explanation is that for $193 \mathrm{~nm}$ excitation the system reaches a vibrationally highly excited state that cannot dissipate its energy quickly enough so that actually thermal chemistry from an excited state occurs. Such thermal chemistry from "hot" vibrational levels in an excited state has been documented recently [22] for systems excited with $193 \mathrm{~nm}$ light, e.g., deviations from the WoodwardHoffman rules [22] for orbital symmetry controlled reactions. Such results are not observed for $248 \mathrm{~nm}$ radiation due to its lower energy.

\subsection{Sulfonium vs iodonium - the chromophore effect}

The difference between the two cations observed in the methacrylate system can at this point only be noted, not fully explained, since it is an inherent property of the respective cation. A detailed photochemical analysis would require high level ab initio calculation of excited state properties, which are currently unavailable. However, it should be noted that only the measurements in the acrylate polymer really reflects the differences in acid generating efficiency between the two cations, since in the DUV polymer the sensitization channel acts as an "equalizer". For example, we have observed the efficiencies of various sulfonium PAGs (similar $\mathrm{E}_{\mathrm{Ted}}$ ) to be very similar in a given $248 \mathrm{~nm}$ resist, whereas

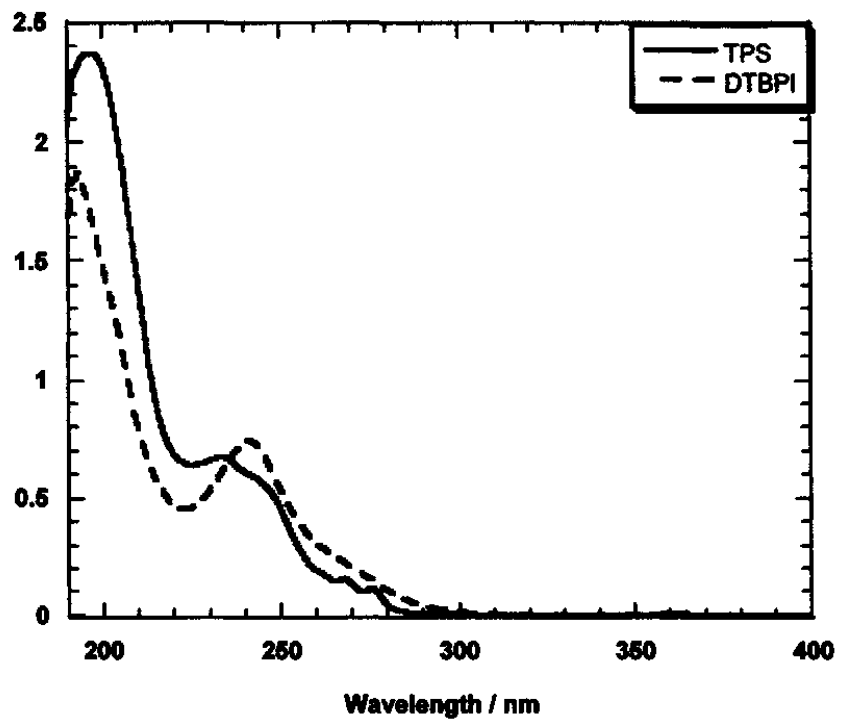

FIGURE 2

the same PAGs in a $193 \mathrm{~nm}$ methacrylate system showed marked differences in photospeed, even if one corrects for the different amounts of the incident light absorbed by the PAGs.

\subsection{The loading effect}

The data shown in Table 1 does not show any significant effect of PAG loading on the quantum yield in the acrylate platform at $193 \mathrm{~nm}$, the observed increase for TPS (0.02) and decrease for DTBPI (0.01) are believed to lie within the noise of our measurements. In contrast, the higher loading increases the efficiency of both PAGs in the phenolic matrix at $248 \mathrm{~nm}$ : 0.06 for TPS and 0.11 for DTBPI. In order to understand the observed trend, we consider the three main loading-related factors that could have an influence on the acid efficiency:

1. The observed rate constant for the decay of the excited state of the sensitizer is a linear function of the quencher concentration, up to the point where it approaches its theoretical limit, which is given by the diffusional rate constant in the respective solvent. This means that an increase in quencher concentration will lead to an increase in total quantum yield of acid generation via the sensitized pathway, unless the maximum quenching efficiency has already been reached with the lower quenching concentration. 
2. The ratio of the contributions of the two acid generating channels depends on the ratio of the absorptions due to the PAG and polymer, i.e., an increase in PAG loading will relatively favor the direct channel due to the increased absorbance of the PAG because the polymer absorbance stays constant. For the low loading, the direct channel has been shown to be more efficient for TPS $\left(\Phi_{\text {acid }}=0.63\right)$ than for DTBPI $\left(\Phi_{\text {acid }}=\right.$ $0.22)$ at $248 \mathrm{~nm}$.

3. There is the possibility of self-quenching of an excited state PAG molecule by another one, i.e., an increase in PAG concentration would lead to a decrease of acid generating efficiency via the direct pathway if self-quenching was operative.

Of course, the two first points are only relevant to the phenolic resist matrix where sensitization is an issue. The absence of any loading effect in the 193 $\mathrm{nm}$ resist system indicates that self-quenching does not occur at the concentrations in our resist. The result obtained for the $248 \mathrm{~nm}$ resist system is in agreement with what can be expected if the first two mechanisms are operational, since both predict an increase in total efficiency with increased loading. The result that the iodonium PAG benefits more from the loading increase suggests that the increase in quenching efficiency plays a more important role than the absorption factor, otherwise the more efficient TPS PAG would have experienced the bigger increase in total efficiency. It may be surprising that of the two concentration dependent intermolecular processes (self-quenching and quenching by electron transfer) only the latter one is significant under our conditions. However, in accordance with our results, the rate constants [23] for self-quenching are usually three to four orders of magnitude smaller than excited state quenching via electron transfer.

\section{Conclusions}

This paper focuses on the difference between quantum yields for acid photogeneration in traditional phenolic (DUV) resists and in acrylate $193 \mathrm{~nm}$ polymers designed for ArF applications. The two PAGs studied, TPS triflate and DTBPI triflate represent standard PAGs widely used throughout the photoresist industry. The method to measure the acid generation quantum yield of these PAGs was based on the C-parameter method. One of the main results from this study is the difference in $248 \mathrm{~nm}$ acid generating efficiency observed between phenolic and acrylate resist platforms depends on the nature of the PAG. This behavior can be attributed to two factors, the first being the presence of two different mechanisms of acid generation, direct and sensitized, in the phenolic system, whereas in the acrylate matrix only the direct pathway exists. The second one is the result that the sensitized pathway is clearly less efficient than direct excitation for the TPS PAG, whereas the difference is very subtle for the iodonium PAG, due to the better electron accepting ability of the latter PAG. The combination of these two trends determines the overall difference in efficiencies observed in the two matrices for the two PAGs.

The results also show that the sulfonium compound by itself, i.e., in a non-sensitizing matrix, is a more efficient acid generator than the iodonium PAG at both wavelengths, a result that is usually masked by the equalizing sensitization effect of the phenolic matrix in $248 \mathrm{~nm}$ resists. Also, it seems that both PAGs are less efficient upon $193 \mathrm{~nm}$ exposure compared to $248 \mathrm{~nm}$ exposure. Finally, a loading effect is only observed in the sensitizing matrix where a higher loading leads to a higher efficiency of the sensitized acid generation pathway, presumably due to more efficient electron transfer between polymer and PAG. This trend is more significant for the iodonium PAG, which is consistent with the more favorable change in free energy for electron transfer from the phenolic matrix to the iodonium PAG as predicted by the RehmWeller equation.

The combination of the effects outlined above explains why efficient acid generation at $193 \mathrm{~nm}$ in an acrylate resist is significantly more challenging compared to DUV resists employing phenolic matrices. If one considers the photospeed that can be achieved with a certain absorption "budget" at the corresponding imaging wavelength, there are two main reasons that favor DUV resists over $193 \mathrm{~nm}$ resists. Firstly, at $193 \mathrm{~nm}$ in an acrylate resist, the light has to be shared between the PAG and a matrix that does not convert the absorbed energy into acid. This scenario is very different to a traditional DUV resist where light is shared between PAG and an active matrix which converts some of its absorbed light into acid via photosensitization. Secondly, the quantum yield of acid generation of these PAGs at $193 \mathrm{~nm}$ is inherently lower than at $248 \mathrm{~nm}$. Some 
ways to overcome these problems are the development of more efficient PAGs, or the use of more transparent polymers.

\section{Acknowledgements}

The authors gratefully acknowledge the support of the Shipley synthesis and formulation groups in this work. We also thank the management and numerous colleagues at Shipley Company for support and helpful suggestions.

\section{References}

1. H. Ito, Proc. SPIE Advances in Resist Technology and Processing XVI, 3678 (1999) 212; H. Ito, J. Photopolym. Sci. Technol., 11 (1998) 379-394; E. Reichmanis, O. Nalamasu, F. M. Houlihan, Acc. Chem. Res., 32 (1999) 659667.

2. K. Nakano, K. Maeda, S. Iwasa, T. Ohfuji, E. Hasegawa, J. Photopolym. Sci. Technol., 10 (1997) 561-570; T. Kajita, H. Ishii, S. Usui, K. Douki, H. Chawanya, T. Shimokawa, $J$. Photopolym. Sci. Technol., 13 (2000) 625-628; K. Nakano, K. Maeda, S. Iwasa, T. Ohfuji, E. Hasegawa, J. Photopolym. Sci. Technol., 13 (2000) 235-236.

3. J. F. Cameron, D. Kang, M. King, J. M. M. Mori, S. Virdee, T. M. Zydowsky, R. F. Sinta, Proc. $10^{\text {th }}$ International Conference on Photopolymers: Principles, Processes and Materials, Society of Plastics Engineers, MidHudson Section, (1997) 120-139.

4. J. F. Cameron, S. L. Ablaza, G. Xu, W. Yueh, Proc. SPIE Advances in Resist Technology and Processing XVI, 3678 (1999) 785-799; J. F. Cameron, S. L. Ablaza, G. Xu, W. Yueh, $J$. Photopolym. Sci. Technol., 12 (1999) 607-620; J. F. Cameron, S. L. Ablaza, G. Xu, W. Yueh, Polym. Mater. Sci. Eng., 81 (1999) 45-46; J. F. Cameron, S. L. Ablaza, G. Xu, W. Yueh, J. Vac. Sci. Technol. Ser. B, 18 (2000) 2543-2550.

5. G. Buhr, R. Dammel, C. R. Lindley, Polym. Mater. Sci. Eng., 61 (1989) 269-277.

6. J. Thackeray, M. Denison, T. Fedynyshyn, D. Kang, R. F. Sinta, ACS Symp. Ser, 614 (Microelectronics Technology) (1995) 110-123.

7. D. R. McKean, U. P. Schaedeli, S. A. MacDonald, Polym. Mater. Sci. Eng., 60 (1989)
45-48; D. R. McKean, U. P. Schaedeli, S. A. MacDonald, ACS Symp. Ser., 412 (Polymers in Microlithography) (1989) 27-38; D. R. McKean, U. P. Schaedeli, S. A. MacDonald, J. Polym. Sci., Part A, Polym. Chem. Ed., 27 (1989) 3927-3935.

8. G. Pohlers, S. Virdee, J. C. Scaiano, R. Sinta, Chem. Mater., 8 (1996) 2654-2658.

9. G. Pohlers, J. C. Scaiano, R. Sinta, Chem. Mater., 9 (1997) 3222-3230.

10. N. Takeyama, Y. Ueda, T. Kusumoto, H. Ueki, M. Hanabata, ACS Symp. Ser., 537 (Polymers for Microelectronics) (1994) 53-63.

11. C. R. Szmanda, R. Kavanagh, J. Bohland, J. Cameron, P. Trefonas, R. Blacksmith, Proc. SPIE Advances in Resist Technology and Processing XVI, 3678 (1999) 857-866; C. R. Szmanda, R. L. Brainard, J. Mackevich, A. Awaji, T. Tanaka, Y. Yamada, J. Bohland, S. Tedesco, B. Dal'Zotto, W. Bruenger, M. Torkler, W. Fallman, H. Loeschner, R. Kaesmaier, P. M. Nealey, A. R. Pawloski, J. Vac. Sci. Technol. Ser. $B, 17$ (1999) 3356-3361.

12. J. F. Cameron, L. Fradkin, K. Moore, G. Pohlers, Proc. SPIE Advances in Resist Technology and Processing XVII, 3999 (2000) 190-203.

13. J. F. Cameron, L. Fradkin, K. Moore, G. Pohlers, Proc. $16^{\text {th }}$ International Conference on Photopolymers: Principles, Processes and Materials, Society of Plastics Engineers, MidHudson Section, (2000), in press.

14. H. Ito, Solid State Technol., 39(7) (1996) 164173; H. Ito, IBM J. Res. Develop., 41 (1997) 6980; J. W. Thackeray, Microelectron. Eng., 41/42 (1998) 37-40.

15. S. Takechi, M. Takahashi, A. Kotachi, K. Nozaki, E. Yano, I. Hanyu, J. Photopolym. Sci. Technol., 9 (1996) 475, and references cited therein.

16. J. Brandrup, E. H. Immergut, E. A. Grulke, (Editors), "Polymer Handbook", $4^{\text {th }}$ edition, Wiley, New York, (1999) V/87, V/91.

17. N. P. Hacker, K. M. Welsh, Proc. SPIE Advances in Resist Technology and Processing VIII, 1466 (1991) 384-393; N. P. Hacker, K. M. Welsh, Adv. Chem. Ser., 236 (1993) 557-572; R. D. Allen, J. Opitz, C. E. Larson, T. I. Wallow, R. A. DiPietro, G. Breyta, R. Sooriyakumaran, D. C. Hofer, J. Photopolym. Sci. Technol., 10 (1997) 503-510.

18. S. L. Murov, I. Carmicheal, G. L. Hug, "Handbook of Photochemistry", $2^{\text {nd }}$ edition, 
Marcel Dekker, New York, (1993).

19. P. S. McKinney, S. J. Rosenthal, J. Electroanal. Chem., 16 (1968) 261.

20. R. J. DeVoe, M. R. V. Sahyun, E. Schmidt, M. Sadrai, N. Serpone, D. K. Sharma, Can. J. Chem., 67 (1989) 1565.

21. A. Weller, Z. Phys. Chem. NF, 133 (1982) 93.
22. W. J. Leigh, B. H. O. Cook, J. Org. Chem., 64 (1999) 5256-5263; E. W. -G. Diau, J. L. Herek, Z. H. K. Ahmed, H. Zewail, Science, 279 (1998) 847-851.

23. N. J. Turro, "Modern Molecular Photochemistry", Benjamin Cummings, Menlo Park, (1978). 